\title{
Adult-onset Still disease: a rare disorder with a potentially fatal outcome
}

\author{
Roberta Priori • Serena Colafrancesco • Angelica Gattamelata • \\ Manuela Di Franco • Ugo Di Tondo• Guido Valesini
}

Received: 9 February 2010 / Accepted: 04 March 2010

(c) Springer-Verlag 2010

\begin{abstract}
Purpose: The aim of this study was to assess the clinical and laboratory features of a cohort of Italian patients with adult-onset Still disease (AOSD) with particular attention on possible life-threatening complications. Methods: The clinical charts of 41 consecutive Italian patients with AOSD referred to our rheumatological department over the last 10 years were retrospectively examined. Data regarding clinical manifestations, laboratory features and complications were collected and compared with those reported in literature. Results: The most frequent manifestations were: fever $(90.2 \%)$, arthralgias $(80.4 \%)$, skin rash $(75.6 \%)$, sore throat $(53.6 \%)$, arthritis $(51.2 \%)$, lymphadenopathy $(48.7 \%)$, hepatosplenomegaly $(41.4 \%)$, myalgia $(21.9 \%)$, fatigue $(12 \%)$, diarrhoea and vomiting $(9.7 \%)$, pleural effusion $(9.7 \%)$, pericardial effusion $(4.8 \%)$ and abdominal pain $(2.4 \%)$. In two patients whose cases are described in detail; the course of the disease was complicated by disseminated intravascu-
\end{abstract}

R. Priori $(\bowtie) \cdot$ S. Colafrancesco $\cdot$ A. Gattamelata $\cdot$ M. Di Franco U. Di Tondo · G. Valesini

UOC Reumatologia,

Policlinico Umberto I, Università La Sapienza,

Viale del Policlinico 00161, Rome, Italy

e-mail: rob.pri@libero.it lar coagulopathy, in one patient with a fatal outcome. ESR, CRP and leucocyte count mean values were $69.41 \mathrm{~mm} / \mathrm{h}, 69.05 \mathrm{mg} / \mathrm{l}$ and $18,798.5 \mathrm{cell} / \mathrm{mm}^{3}$ (neutrophils $84.64 \%$ ), respectively. Serum ferritin levels were increased in $48.7 \%$ of patients while transaminases were elevated in $42.6 \%$ of patients $(71 \%$ considering only patients in an active phase of disease). Conclusion: The results of this study are in line with those reported for other cohorts of patients. Even if the prognosis of AOSD is considered favourable, the present study indicates that the disease is a troubling condition needing prompt intervention. Occasionally, AOSD may rapidly worsen with life-threatening events.

Keywords Adult-onset Still disease · Fever · Autoinflammatory diseases · Disseminated intravascular coagulation . Myocarditis

\section{Introduction}

Adult-onset Still's disease (AOSD) is a rare systemic inflammatory disorder of unknown aetiology characterized by a typical triad of symptoms including daily high spiking fever, evanescent salmon-pink rash and arthritis/arthralgias. It usually occurs in young people between 16 and 35 years of age [1]; women are affected slightly more frequently than men [2-4]. The aetiology of AOSD has not been elucidated, but a combination of genetic and infectious factors in the setting of an immune dysregulation has been suggested with an alteration in cytokine production in favour of a Th1 predominance [5]. IL-18, a proinflammatory and immunoregulatory cytokine, seems to play a pivotal role in promoting the systemic inflammatory process in AOSD [6], and its serum level is 
increased in affected patients correlating with disease activity [7-9]. Moreover, IL-18 overexpression has been detected in effector target tissues from a variety of autoimmune inflammatory diseases, and we have recently shown that IL-18 is expressed at higher levels in AOSD lymph nodes as compared to nonspecific lymphadenitis and normal lymph nodes [10].

Several sets of classification criteria have been proposed, the most commonly used being the "Yamaguchi" criteria [11]. However, diagnosis is sometimes challenging, and treatment can be even more difficult. In addition to the classical clinical triad, patients with AOSD can present a constellation of other symptoms, including sore throat, hepatitis, myalgia, serositis, pulmonary manifestations, heart and kidney involvement, abdominal pain, neurological and haematological complications. Moreover, hepatomegaly, splenomegaly and lymphoadenopathy can be seen $[12,13]$. Although mortality in AOSD is quite low, a fatal outcome has been reported in some patients [2, 14-28].

In the present study, we analysed the clinical and laboratory features of an cohort of Italian patients with AOSD and describe in detail two difficult cases, both complicated with disseminated intravascular coagulopathy (DIC), in one case with a fatal outcome.

\section{Patients and methods}

The clinical charts of all patients with AOSD (diagnosed according to the Yamaguchi criteria [11]) referred to the Rheumatology Unit of Sapienza University of Rome over the last 10 years were retrospectively examined. In all patients investigations were carried out in order to rule out infections, malignancies, and other rheumatic diseases. A complete general laboratory work-up, including rheumatoid factor (RF) and antinuclear autoantibodies (ANA), ultrasonography of the abdomen, and chest radiography, was performed in all patients. Joint radiography and ultrasonography, CT scanning, MR imaging, echocardiography, and other specific tests were added if needed on clinical grounds. The clinical manifestations at presentation and the laboratory features were reviewed and recorded using a standardized form for analysis. Disease activity was calculated according to the criteria described by Pouchot et al. in 1991 [14].

\section{Results}

41 patients were considered (23 women/18 men; 21 outpatients/20 hospitalized). The mean age of the patients on admission was 39.5 years (range 18-66 years) and the age at onset ranged from 16 to 64 years (mean 34.8 years).

As expected the most frequent manifestation at the very onset was fever $(73 \%)$ followed by arthralgia $(63.4 \%)$, skin rash $(46.3 \%)$, sore throat $(34 \%)$ and arthritis $(29.2 \%)$. However, during follow-up, fever appeared in 37 out of 41 patients $(90.2 \%)$, arthralgias in 33 $(80.4 \%)$, skin rash in $31(75.6 \%)$, sore throat in 22 (53.6\%), arthritis in $21(51.2 \%)$, myalgia in $9(21.9 \%)$ and fatigue in 5 (12\%), Only five patients had abdominal symptoms, four with diarrhoea and vomiting $(9.75 \%)$ and one with abdominal pain $(2.43 \%)$. Of the 41 patients, 20 (48.7\%) had lymphadenopathy, 17 hepatosplenomegaly $(41.4 \%), 4$ pleural effusion $(9.75 \%)$ and 2 pericardial effusion $(4.8 \%)$ (Table 1). The classical triad of symptoms (fever, rash and arthritis/arthralgia) was finally found in 28 patients $(68.2 \%)$. The most commonly affected joints were the hand joints (metacarpophalangeal and proximal interphalangeal) in 19 patients $(46.3 \%)$, knee in 18 patients $(43.9 \%)$, wrist in 13 patients $(31.7 \%)$, ankle in 13 patients $(31.7 \%)$, foot in 6 patients $(14.6 \%)$, shoulder in 4 patients $(9.7 \%)$ and temporomandibular joint in 2 patients $(4.8 \%)$ (Table 2$)$.

ESR was $69.41 \pm 28.77 \mathrm{~mm} / \mathrm{h}($ mean $\pm \mathrm{SD})$, and $\mathrm{C}$ reactive protein $(\mathrm{CRP})$ was $69.05 \pm 78.73 \mathrm{mg} / \mathrm{l}$. Serum ferritin levels were increased above the normal value in 20 patients $(48.7 \%)$ with a mean value of $5,641.95 \pm 8,339.39$ $\mathrm{ng} / \mathrm{ml}$, being $>1,000 \mathrm{ng} / \mathrm{ml}$ in 14 patients $(34 \%),>5,000$ $\mathrm{ng} / \mathrm{ml}$ in 8 patients $(19.5 \%)$ and $>8,000 \mathrm{ng} / \mathrm{ml}$ in 4 patients $(9.7 \%)$. Ferritin levels were correlated with disease activity as calculated by Pouchot criteria [14] (Spearman's test, $p=0.006$ ). The mean leucocyte count was $18,798.5 \pm 7,031$ cell $/ \mathrm{mm}^{3}$ (neutrophils $84.64 \pm 6.95 \%$ ), being $>10,000 / \mathrm{mm}^{3}$ in 18 patients $(43.9 \%),>15,000 / \mathrm{mm}^{3}$ in 13 patients $(31.7 \%)$ and $>18,000 / \mathrm{mm}^{3}$ in 12 patients $(29.2 \%)$. Transaminases were twice the normal values in $42.6 \%$ of patients $(71 \%$ considering only patients in an active phase of the disease). In all patients ANA and RF were absent (Table 3).

All patients were treated orally or intravenously with corticosteroids, in $39.3 \%$ of patients in combination with methotrexate (10-15 mg/week), in $25 \%$ of patients in combination with cyclosporin A (3-5 mg/kg per day) orally, and in two patients with both. Four patients $(9.7 \%)$ had disease resistant to the traditional approach and were treated with newer biological drugs with benefit: etanercept in two patients and anakinra in the other two patients [29].

\section{Case 1}

A 34-year-old Caucasian woman presented with a 2month history of high fever (up to $40^{\circ} \mathrm{C}$ ), skin rash of the 
Table 1 Clinical features of 41 italian AOSD in comparison to previously published case series

\begin{tabular}{|c|c|c|c|c|c|c|c|c|c|c|}
\hline Clinical manifestations & $\begin{array}{r}\text { Present } \\
\text { study } \\
(n=41)\end{array}$ & $\begin{array}{r}\text { Masson } \\
{[35]} \\
(n=65)\end{array}$ & $\begin{array}{r}\text { Pouchot } \\
{[14]} \\
(n=62)\end{array}$ & $\begin{array}{r}\text { Wouters } \\
{[42]} \\
(n=45)\end{array}$ & $\begin{array}{r}\text { Ohta } \\
{[2]} \\
(\mathbf{n}=90)\end{array}$ & $\begin{array}{r}\text { Zeng } \\
{[17]} \\
(\mathbf{n}=61)\end{array}$ & $\begin{array}{r}\text { Guihua } \\
{[18]} \\
(n=77)\end{array}$ & $\begin{array}{r}\text { Cagatay } \\
{[44]} \\
(n=84)\end{array}$ & $\begin{array}{r}\text { Reginato } \\
{[16]} \\
(\mathbf{n}=23)\end{array}$ & $\begin{array}{r}\text { Franchini } \\
{[28]} \\
(n=66)\end{array}$ \\
\hline Female (n/\%) & $23 / 56$ & $34 / 52,3$ & $28 / 45,1$ & $27 / 60$ & $67 / 74,4$ & $45 / 73,7$ & $54 / 70$ & $59 / 70$ & $11 / 47,8$ & $38 / 58$ \\
\hline Mean age at onset (y) & 34,8 & 21 & 24 & 25 & 32 & 37,5 & 32,6 & 33 & ns & 37 \\
\hline Fever $(\%)$ & 90,2 & 94 & 100 & 100 & 100 & 100 & 96,1 & 95 & 100 & 95 \\
\hline Arthralgia (\%) & 80,4 & 100 & 100 & ns & 100 & ns & 87 & 96 & ns & 100 \\
\hline $\operatorname{Rash}(\%)$ & 75,6 & 85 & 87 & 82 & 87 & 88,5 & 85,7 & 60 & 95,6 & 79 \\
\hline Arthritis (\%) & 51,2 & 69 & 94 & 98 & 72 & 82 & 87 & 69 & 100 & 79 \\
\hline Lymphadenopathy (\%) & 48,7 & 48 & 74 & 71 & 69 & 52,5 & 45,5 & 33 & 52,1 & 54 \\
\hline Hepatomegaly (\%) & 41,4 & 9 & 44 & ns & 48 & 13,1 & 11,7 & 38 & 26 & 41 \\
\hline Splenomegaly (\%) & 41,4 & 22 & 55 & 36 & 65 & 37,7 & 28,6 & 29 & 21,7 & 38 \\
\hline Myalgia (\%) & 21,9 & 62 & 84 & 75 & 56 & 27,9 & 55 & 13 & 34,7 & 70 \\
\hline Pleuritis (\%) & 9,7 & 15 & 53 & 25 & 12 & 18 & 11,7 & 10 & 21,7 & 18 \\
\hline Pericarditis (\%) & 4,8 & 23 & 37 & 22 & 1 & 24,6 & 2,6 & 12 & 21,7 & 14 \\
\hline Abdominal pain $(\%)$ & 2,4 & ns & 48 & ns & ns & ns & 20,8 & 1 & 8,6 & 24 \\
\hline Pneumonitis (\%) & 2,4 & ns & 27 & ns & 6 & 4 & ns & 4 & 17,3 & 5 \\
\hline
\end{tabular}

NS not stated

Table 2 Articular involvement detected in our cohort in comparison to others

\begin{tabular}{|c|c|c|c|c|c|}
\hline Involvement of & $\begin{array}{r}\text { Present study } \\
\qquad(\mathrm{n}=\mathbf{4 1})\end{array}$ & $\begin{array}{r}\text { Pouchot [14] } \\
(n=62)\end{array}$ & $\begin{array}{r}\text { Cagatay }[44] \\
(n=84)\end{array}$ & $\begin{array}{r}\text { Masson [35] } \\
(n=65)\end{array}$ & $\begin{array}{r}\text { Franchini [28] } \\
(n=66)\end{array}$ \\
\hline Knee & $43,9 \%$ & $82 \%$ & $51,1 \%$ & $69 \%$ & $65 \%$ \\
\hline Wrist & $31,7 \%$ & $73 \%$ & $42,8 \%$ & $67 \%$ & $56 \%$ \\
\hline Ankle & $31,7 \%$ & $55 \%$ & $39,3 \%$ & $38 \%$ & $52 \%$ \\
\hline PIP & $46,3 \%$ & $47 \%$ & $21,4 \%$ & $44 \%$ & $37 \%$ \\
\hline Shoulder & $9,7 \%$ & $40 \%$ & $13,1 \%$ & $24 \%$ & $27 \%$ \\
\hline $\mathrm{MCP}$ & $46,3 \%$ & $35 \%$ & $21,4 \%$ & $42 \%$ & $29 \%$ \\
\hline MTP & $14,6 \%$ & $18 \%$ & $10,7 \%$ & $11 \%$ & $12 \%$ \\
\hline TMJ & $4,8 \%$ & $3 \%$ & NS & $4 \%$ & $8 \%$ \\
\hline
\end{tabular}

PIP, proximal interphalangeal; MCP, metacarpophalangeal; MTP, metatarsophalangeal, TMJ temporomandibular joint

Table 3 Laboratory findings in the 41 patients with AOSD in this study

\begin{tabular}{lrr}
\hline & Mean & SD \\
\hline ESR $(\mathrm{mm} / \mathrm{h})$ & 69.41 & 28.77 \\
CRP $(\mathrm{mg} / \mathrm{l})$ & 69.05 & 78.73 \\
Ferritin (ng/ml) & $5,641.95$ & $8,339.39$ \\
Leucocytes (cell/mm $\left.\mathrm{mm}^{3}\right)$ & $18,798.5$ (neutrophils $84.64 \%)$ & $7,031.91$ \\
AST (U/l) & 66.3 & 82.16 \\
ALT (U/l) & 93.76 & 111.55 \\
\hline
\end{tabular}

arms and hands, myalgia, wrist arthritis and sore throat. ESR was $95 \mathrm{~mm} / \mathrm{h}$, CRP $341 \mathrm{mg} / \mathrm{l}$, WBC 35,900/. $\mathrm{mm}^{3}$, AST $101 \mathrm{U} / 1$ and ALT $113 \mathrm{U} / \mathrm{l}$. Serum ferritin was markedly elevated at $23,849 \mathrm{ng} / \mathrm{ml}$. She was initially hospitalized in the Department of Infectious Disease where an extensive work-up (including $\mathrm{HIV}, \mathrm{HBV}$ and $\mathrm{HCV}$, CMV, EBV, Salmonella, Brucella, and blood, urine and stool cultures) was negative. Transthoracic echocardiography was normal. A total body CT scan revealed diffuse lymphoadenomegaly, splenomegaly, hepatomegaly and a small amount of bilateral pleural effusion. On the hypothesis of AOSD, prednisolone $40 \mathrm{mg}$ was started with no amelioration of symptoms. The patient was moved to our department for further evaluation.

On admission the patient was spikingly febrile (up to $40^{\circ} \mathrm{C}$ ) and the spikes were always associated with the typical skin rash on the arms, legs, trunk and face. Arthritis of both wrists was still present. High-dose intravenous methylprednisolone was started (250 mg daily) with only a partial improvement of arthritis. During the second day of hospitalization, she showed hypotension (blood pressure $80 / 50 \mathrm{mmHg}$ ), severe dyspnoea, and oliguria. Her WBC was $29,000 / \mathrm{mm}^{3}$, haemoglobin decreased to $10 \mathrm{~g} / \mathrm{dl}$, platelets decreased to $79,000 / \mathrm{mm}^{3}$, INR was 2.36 , fibrinogen was $150 \mathrm{mg} / \mathrm{dl}$, and antithrombin III was decreased (49\%). A smear of peripheral venous blood excluded a macrophage activation syndrome. Her condition rapidly deteriorated with the progressive development of DIC. The patient was treated with fresh frozen plasma, antithrombin III and dexamethasone, and was then admitted to the intensive care unit where she died a few hours later.

Autopsy showed severe myocarditis (Fig. 1), serofibrinous pericarditis, confluent foci of pneumonic infil- 


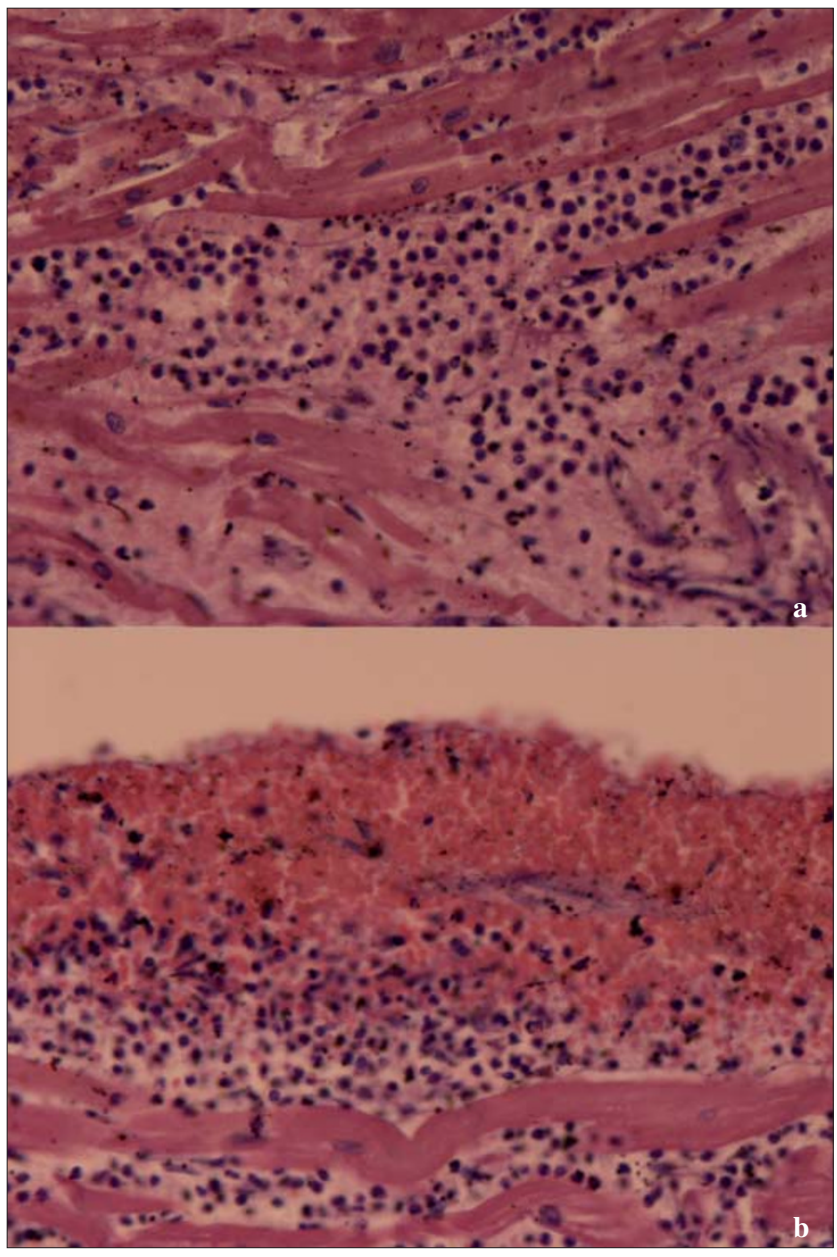

Fig. 1 Myocardium. a Muscle fibres are dissociated by an abundant inflammatory infiltrate of lymphocytes/monocytes (haematoxylineosin, medium magnification). b At the top the endocardium shows infiltration of blood and a lymphocytic/monocytic inflammatory exudate, and below the muscle cells are dissociated by an infiltrate of lymphocytes/monocytes (haematoxylin-eosin, medium magnification)

trates and areas of atelectasia, serofibrinous bilateral pleuritis, diffuse subpleural petechiae and subendothelial bleeding in the gastric mucosa, and hyperplasia of the spleen and of the inguinal and axillary lymph nodes. We had the opportunity to measure the serum IL-18 level with a commercial ELISA kit (Immuno Pharmacology Research, Italy), and detected a very high value (1,236.9 $\mathrm{pg} / \mathrm{ml}$ ) in comparison to $189 \mathrm{pg} / \mathrm{ml}$ (range 0-144 pg/ml) in the serum from 21 healthy blood donors.

\section{Case 2}

A 42-year-old Caucasian woman presented with an erythematous transitory skin rash localized mainly on her face, arthralgia involving the wrists and knees, sore throat and spiking fever up to $39^{\circ} \mathrm{C}$. ESR was $27 \mathrm{~mm} / \mathrm{h}, \mathrm{CRP}$ was $173.5 \mathrm{mg} / \mathrm{l} \mathrm{WBC}$ was $19,620 / \mathrm{mm}^{3}$ and ferritin was
$508 \mathrm{ng} / \mathrm{ml}$. Broad-spectrum antibiotic treatment was administered without resolution of the fever. She was admitted to the Department of Infectious Disease where, after an extensive diagnostic work-up, neoplastic, infectious and other connective tissue diseases were reasonably excluded. Transoesophageal echocardiography showed a moderate left atrial dilatation and mild aortic and mitral regurgitation. AOSD was suspected and oral prednisone $50 \mathrm{mg}$ was started with only partial and transitory improvement. Four days later the patient developed a DIC with a reduction in platelets, haemoglobin and antithrombin III, and increased transaminases (AST 404 U/l, ALT 231 U/l). Triglyceride levels were normal and ferritin remained stable at a high value. A peripheral blood smear was normal. Fresh frozen plasma and antithrombin III were given with benefit.

Later, because of a rapid worsening of haemodynamic condition, she was admitted to the intensive care unit where transthoracic echocardiography demonstrated a global severe hypokinesia of the myocardium. High-frequency atrial fibrillation developed. The patient underwent electrical cardioversion and a mechanical intraaortic balloon counterpulsation was introduced. Cardiac MR imaging showed a subacute myocarditis. Intravenous methylprednisolone $250 \mathrm{mg}$ was started. The patient gradually improved and the corticosteroid was tapered. Over the subsequent months, the patient experienced a relapse of fever, arthritis and rash whenever steroid treatment was reduced. Methotrexate $15 \mathrm{mg}$ weekly was prescribed with benefit, and at the time of this report the patient was still in complete remission without corticosteroid.

\section{Discussion}

The prevalence of AOSD seems to be low in Italy, and only one large cohort of italian patients has been very recently published [28]. In Japan, the prevalence among men and women over the age of 16 years has been estimated to be $0.73 / 100,000$ and $1.47 / 100,000$, while the crude incidence rates are 0.22 and 0.34 , respectively [30]. The yearly incidence in the Caucasian population seems to be lower [31]. Description of cases from several countries is important as inflammatory diseases often have different clinical expressions in people of different ethnicities, and also in AOSD the clinical presentation in Western countries is slightly different from that in Eastern countries [28, 32-34].

The clinical triad of symptoms typical of AOSD (fever, joint involvement and skin rash) was frequently present in our population and, as expected, fever was the predominant feature (Table 1). Actually, AOSD is one of 
the possible causes of long-standing fever of unknown origin. Joint involvement was present in the majority of patients in the form of diffuse arthralgia, while arthritis appeared in only half of the patients. The hand was slightly more frequently impaired than the knee, which has been reported as the joint primarily affected in AOSD [14, 35] (Table 2). Erosions were not detected and serum RF was always absent. In two patients with severe joint involvement resistant to conventional treatment, administration of the IL-1 receptor antagonist anakinra resulted in sustained remission. In these patients, the benefit of IL-1 blockade on arthritis was confirmed by musculoskeletal ultrasonography [29]. Skin rash was the third most prevalent symptom (Fig. 2), usually appearing during the feverish attack and generally responding to steroid treatment.

A significant neutrophilic leucocytosis associated with an increase in ESR, CRP and ferritin values are almost invariably detected in patients with active AOSD, and this finding was confirmed in our cohort. Hyperferritinaemia seems to be the main feature of AOSD in which it can reach very high concentrations especially in those patients with reactive haemophagocytosis syndrome. In our survey, very high ferritin values $(>5,000 \mathrm{ng} / \mathrm{ml})$ were found in $20 \%$ of the patients, and its concentration was significantly correlated with disease activity.

An increase in hepatic enzymes was recorded in almost three-quarters of our patients with active AOSD. This finding is in line with the findings of other studies in which liver involvement has been found in 40-90\% of patients $[14,18,36]$. The mild hepatitis found in AOSD is often characterized by moderate abnormalities in liver biochemistry, such as elevation in transaminases and cholestasis, while, more rarely, severe cytolysis and subsequent death occur $[14,16-18,23,24]$ in accordance with the observation in our cohort where no patient showed hepatic failure. Severe liver involvement can occasionally be related to the concomitant use of potential hepatotoxic drugs such as sulphasalazine, NSAIDs, aspirin and cyclosporine [14, 16, 23, 37-41].
In the present cohort, $5 \%$ of patients $(2 / 41)$ experienced life-threatening complications such as DIC, adult respiratory distress syndrome (ARDS) and heart involvement requiring intensive care. As far as we know, 16 fatalities have been reported among the largest eleven cohorts including 618 patients with AOSD published so far (mortality 2.6\%, range, 0-9.83\%) [2, 14-18, 28, 35, 42, 43, 44].

Establishing the precise, final cause of death is not always possible as the patient may finally present a multiorgan failure which can be difficult to differentiate from a septic state. DIC is one of the most dramatic events in AOSD and is a possible cause of death [2, 18, 20, 22, 28] although complete recovery in several patients has been reported $[2,14,22,35,42,45-50]$. It can follow or be associated with reactive haematophagocytic syndrome (RHS), a further possible life-threatening complication in AODS [15, 17, 21, 22, 43, 51]. This event is characterized by an uncontrolled and sustained activation of macrophages associated with impairment of cytotoxic function with a true cytokine storm [22]. Leucopoenia, thrombocytopenia, hypertriglyceridaemia and very high ferritin values can be considered as red flags for RHS although there is no established set of criteria for its diagnosis in adults. In the two patients whose cases are described in detail, RHS was excluded because of significant leucocytosis and no increase in triglycerides, and a completely normal peripheral blood smear, although bone marrow aspiration, which is considered a sensitive diagnostic procedure for RHS, was not performed. Arlet et al. [22] recently described six patients with AOSD and associated RHS, one with a fatal outcome, suggesting that RHS may go under-diagnosed in AOSD. Some authors have proposed that AOSD, its paediatric variant systemic onset juvenile idiopathic arthritis (SoJIA) and RHS are indeed the same disease in different clinical presentations but with essentially the same physiopathogenesis [52].

The autopsy performed in the patient who died demonstrated multiorgan involvement with clear evidence of myopericarditis and lung involvement. The patient was


Fig. 2 AOSD transitory skin rash 
dyspnoeic and hypoxic and showed multiple pulmonary infiltrates as is seen in ARDS. Three other cases of fatal AOSD and ARDS have been described in one case associated with RHS [22, 25, 26]. Myocarditis [14, 16, 20, 35, $46,53-55]$, and in particular cardiac tamponade [45], can also very rarely complicate the course of AOSD, more frequently appearing in the paediatric form. Indeed, in SoJIA, myocarditis is a well-known complication often associated with pericardial effusion, which can lead to congestive heart failure and arrhythmias. In AOSD heart involvement is generally represented by chronic myocarditis, leading to progressive dilatation and subsequent heart failure. In the first case presented above, the diagnosis of myocarditis was histologically confirmed post mortem while in the second case the diagnosis was made on clinical grounds and the patient responded to high-dose corticosteroids as previously described [54, 56]. High-dose intravenous immunoglobulin therapy may also be useful in acute Still's myocarditis [57], but evidence is still inconclusive [58].

Other possibly fatal complications, such as thrombotic thrombocytopoenic purpura [59], haemolytic uraemic syndrome [60], and neurological complications such as aseptic meningoencephalitis $[2,61]$, neuropathy $[14,16$, 62] and status epilepticus [19], have been described in AOSD, but were not detected in our cohort.

In conclusion, we have described the phenotype of AOSD in a large Italian cohort of patients with particular attention on possible life-threatening complications that may occur during the course of the disease.

Although the prognosis of AOSD is generally considered favourable, the present report suggests that the disease represents a troubling condition needing prompt intervention and the use of biological drugs in some selected patients with refractory disease. Occasionally, AOSD may rapidly worsen with life-threatening events. Although these complications are rather rare, early identification is of the utmost importance in order to halt evolution of the disease and prevent a possible fatal outcome.

Conflict of interest statement The authors declare that they have no conflict of interest related to the publication of this article.

Aknowledgement We thank Dr Cristiano Alessandri for his kind help.

\section{References}

1. Ohta A, Yamaguchi M, Kaneoka H et al (1987) Adult Still's disease: review of 228 cases from the literature. J Rheumatol 14:1139-1146

2. Ohta A, Yamaguchi M, Tsunematsu T et al (1990) Adult Still's disease: a multicenter survey of Japanese patients. J Rheumatol 17:1058-1063

3. Efthimiou P, Paik PK, Bielory L (2006) Diagnosis and management of adult onset Still's disease. Ann Rheum Dis 65:564-572
4. Kàdàr J, Petrovicz E (2004) Adult-onset Still's disease. Best Practice \& Research Clinical Rheumatology 18:663-676

5. Chen DY, Lan JL, Lin FJ et al (2004) Predominance of Th1 cytokine in peripheral blood and pathological tissues of patients with active untreated adult onset Still's disease. Ann Rheum Dis 63:1300-1306

6. Bombardieri M, McInnes IB, Pitzalis C (2007) Interleukin-18 potential therapeutic target in chronic autoimmune/inflammatory conditions. Expert Opin Biol Ther 7:31-40

7. Chen DY, Lan JL, Lin FJ et al (2004) Proinflammatory cytokine profiles in sera and pathological tissues of patients with active untreated adult onset Still's disease. J Rheumatol 31:2189-2198

8. Kawaguchi Y, Terajima H, Harigai M et al (2001) Interleukin18 as a novel diagnostic marker and indicator of disease severity in adult-onset Still's disease. Arthritis Rheum 44:1716-1718

9. Kawashima M, Yamamura M, Taniai M et al (2001) Levels of interleukin-18 and its binding inhibitors in the blood circulation of patients with adult-onset Still's disease. Arthritis Rheum 44:550-560

10. Conigliaro P, Priori R, Bombardieri M et al (2009) Lymph node IL-18 expression in adult onset Still's disease. Ann Rheum Dis 68:442-443

11. Yamaguchi M, Ohta A, Tsunematsu T et al (1992) Preliminary criteria for classification of adult Still's disease. J Rheumatol 19:424-430

12. Kontzias A, Efthimiou P (2008) Adult-onset Still's disease: pathogenesis, clinical manifestations and therapeutic advances. Drugs 68:319-337

13. Fautrel B (2008) Adult-onset Still disease. Best Pract Res Clin Rheumatol 22:773-792

14. Pouchot J, Sampalis JS, Beaudet F et al (1991) Adult Still's disease: manifestations, disease course, and outcome in 62 patients. Medicine (Baltimore) 70:118-36

15. Singh S, Samant R, Joshi VR (2008) Adult onset Still's disease: a study of 14 cases. Clin Rheumatol 27:35-39

16. Reginato AJ, Schumacher HR Jr, Baker DG et al (1987) Adult onset Still's disease: experience in 23 patients and literature review with emphasis on organ failure. Semin Arthritis Rheum 17(1:39-57

17. Zeng T, Zou YQ, Wu MF et al (2009) Clinical features and prognosis of adult onset Still's disease: 61 cases from China. J Rheumatol 36:1026-31

18. Zhu G, Liu G, Liu Y et al (2009) Liver abnormalities in adult onset Still's disease: a retrospective study of 77 Chinese patients. J Clin Rheumatol 15:284-288

19. Hong YH, Lee CK (2008) A case of adult onset Still's disease with systemic inflammatory response syndrome complicated by fatal status epilepticus. Rheumatol Int 28:931-933

20. Colina M, Govoni M, Trotta F (2009) Fatal myocarditis in adultonset Still's disease with diffuse intravascular coagulation. Rheumatol Int 29:1355-7

21. Gianella S, Schaer DJ, Schwarz U et al (2008) Retinal microangiopathy and rapidly fatal cerebral edema in a patient with adultonset Still's disease and concurrent macrophage activation syndrome. Am J Hematol 83:424-427

22. Arlet JB, Le TH, Marinho A et al (2006) Reactive haemophagocytic syndrome in adult-onset Still's disease: a report of six patients and a review of the literature. Ann Rheum Dis 65:1596-1601

23. Dino O, Provenzano G, Giannuoli G et al (1996) Fulminant hepatic failure in adult onset Still's disease. J Rheumatol 23:784-785

24. Thabah MM, Singh KK, Madhavan SM et al (2008) Adult onset Still's disease as a cause of acute liver failure. Trop Gastroenterol 29:35-36 
25. Hirohata S, Kamoshita H, Taketani T et al (1986) Adult Still's disease complicated with adult respiratory distress. Arch Intern Med 146:2409-2410

26. Stoica GS, Cohen RI, Rossof LG (2002) Adult Still's disease and respiratory failure in a 74 year old woman. Postgrad Med J 78:97-98

27. Mejjad O, Vittecoq O, Tamion F et al (2001) A shock associated with adult onset Still's disease. Joint Bone Spine 68:76-78

28. Franchini S, Dagna L, Salvo F, Aiello P, Baldissera E, Sabbadini MG (2010) Adult onset Still's disease: clinical presentation in a large cohort of italian patients. 28:41-48

29. Priori R, Ceccarelli F, Barone F et al (2008) Clinical, biological and sonographic response to IL-1 blockade in adult onset Still's disease. Clin Exp Rheumatol 26:933-937

30. Wakai K, Ohta A, Tamakoshi A et al (1997) Estimated prevalence and incidence of adult Still's disease: findings by a nationwide epidemiological survey in Japan. J Epidemiol 7:221-225

31. Magadur-Joly G, Billaud E, Barrier JH et al (1995) Epidemiology of adult Still's disease: estimate of the incidence by a retrospective study in west France. Ann Rheum Dis 54:587-590

32. Louthrenoo W, Aramsareewong T, Sukitawut W (2001) Adult onset Still's disease: clinical features and outcome in 16 Thai patients. J Clin Rheumatol 7:301-307

33. Uppal SS, Pande IR, Kumar A et al (1995) Adult onset Still's disease in northern India: comparison with juvenile onset Still's disease. Br J Rheumatol 34:429-34

34. Uppal SS, Al-Mutairi M, Hayat S et al (2007) Ten years of clinical experience with adult onset Still's disease: is the outcome improving? Clin Rheumatol 26:1055-1060

35. Masson C, Le loet X, Liote F et al (1995) Adult Still's disease: part I. Manifestations and complications in sixty-five cases in France. Rev Rhum Engl Ed 62:748-757

36. Andres E, Kurtz JE, Perrin AE et al (2003) Retrospective monocentric study of 17 patients with adult Still's disease, with special focus on liver abnormalities. Hepatogastroenterology 50:192-195

37. McFarlane M, Harth M, Wall WJ (1997) Liver transplantation in adult Still's disease. J Rheum 24:2038-2041

38. Ott SJ, Baron A, Berghaus T et al (2003) Liver failure in adult Still's disease during corticosteroid treatment. Eur J Gastroenterol Hepatol 15:87-90

39. Jung JH , Jun JB, Yoo DH et al (2000) High toxicity of sulfasalazine in adult-onset Still's disease. Clin Exp Rheumatol 18:245-248

40. Crowley J, Situnayake RD (1992) Sulphasalazine induced hepatitis in adult Still's disease. Ann Rheum Dis 51:1264-1265

41. Janssen HL, van Laar JM, van Hoek B et al (1999) Severe hepatitis and pure red cell aplasia in adult Still's disease: good response to immunosuppressive therapy. Dig Dis Sci 44:1639-1642

42. Wouters JM, van de Putte LB (1986) Adult-onset Still's disease: clinical and laboratory features, treatment and progress of 45 cases. Q J Med 61:1055-1065

43. Mehrpoor G, Owlia MB, Soleimani H et al (2008) Adult onset Still's disease: a report of 28 cases and review of the literature. Mod Rheumatol 18:480-485

44. Catagay Y, Gul A, Catagay A et al (2009) Adult-onset Still's disease. Intern J Clin Pract 63:1050-1055

45. Ames PR, Walker E, Aw D et al (2009) Multi-organ failure in adult onset Still's disease: a septic disguise. Clin Rheumatol 28 (Suppl 1):S3-S6

46. Krzossok S, Benck U, Van Der Woude FJ et al (2004) Disseminated intravascular coagulation, perimyocarditis and empyema in adult onset Still's disease. Dtsch Med Wochenschr 129:2535-2537

47. Aray Y, Handa T, Mitani K (2004) Adult onset Still's disease presenting with disseminated intravascular coagulation. Rinsho Ketsueki 45:316-318

48. Park JH, Bae JH, Choi YS et al (2004) Adult-onset Still's disease with disseminated intravascular coagulation and multiple organ dysfunctions dramatically treated with cyclosporine A. J Korean Med Shi 19:137-141

49. Yokoyama M, Suwa A, Shinozawa T et al (1995) A case of adult onset Still's disease complicated with adult respiratory distress syndrome and disseminated intravascular coagulation. Nihon Rinsho Meneki Gakkai Kaishi 18:207-214

50. Iglesias J, Sathiraju S, Marik PE (1999) Severe systemic inflammatory response syndrome with shock and ARDS resulting from Still's disease: clinical response with high dose pulse methylprednisolone therapy. Chest 115:1738-1740

51. Takeshita A, Takeuchi T, Nakagawa A et al (2000) Adult onset Still's disease with hemophagocytic syndrome and severe liver dysfunction. Hepatol Res 17:139-144

52. Félix FH, Leal LK, Fontenele JB (2009) Cloak and dagger: the case for adult onset Still disease and hemophagocytic lymphohistiocytosis. Rheumatol Int 29:973-974

53. Cavallasca JA, Vigliano CA, Perandones CE et al (2009) Myocarditis as a form of relapse in two patients with adult Still's disease. Rheumatol Int. DOI: 10.1007/s00296-009-1031-3

54. Vandergheinst F, Gosset J, Van de Borne P et al (2005) Myopericarditis revealing adult onset Still's disease. Acta Clin Belg 60:205-208

55. Nishimagi E, Hirata S, Kawaguchi Y et al (2004) Myocardial dysfunction in a patient with adult onset Still's disease. Clin Exp Rheumatol 22:506-507

56. Hosaka S, Takashina N, Ishikawa A et al (1992) Adult Still's disease with myocarditis and peritonitis. Intern Med 31:812-815

57. Kuek A, Weerakoon A, Ahmed K et al (2007) Adult-onset Still's disease and myocarditis: successful treatment with intravenous immunoglobulin and maintenance of remission with etanercept. Rheumatology (Oxford) 46:1043-1044

58. Prieur AM (1996) Intravenous immunoglobulins in Still's disease: still controversial, still unproven. J Rheumatol 23:797-800

59. Perez MG, Rodwing FR Jr (2003) Chronic relapsing thrombotic thrombocytopenic purpura in adult onset Still's disease. South Med J 96:46-49

60. Diamond JR (1997) Hemolytic uremic syndrome/thrombotic thrombocytopenic purpura complicating adult Still's Disease: remission induced with intravenous immunoglobulin g. J Nephrol 10:253-257

61. Denault A, Dimopoulos MA, Fitzcharles MA (1990) Meningoencephalitis and peripheral neuropathy complicating adult Still's disease. J Rheumatol 17:698-700

62. Markusse HM, Stolk B, Van der Mey AG et al (1988) Sensorineural hearing loss in adult Still's disease. Ann Rheum Dis 47:600-602 